\title{
ANÁLISE ESPAÇO-TEMPORAL DO ESTADO DE CONSERVAÇÃO DA ÁREA DE PROTEÇÃO AMBIENTAL LAGOAS E DUNAS DO ABAETÉ
}

\author{
SPATIAL AND TEMPORAL ANALYSIS OF THE STATE OF CONSERVATION OF LAGOAS E \\ DUNAS DO ABAETÉ ENVIRONMENTAL PROTECTION AREA
} \author{
diegoidelfonso@hotmail.com; fraga.pereira@ufba.br

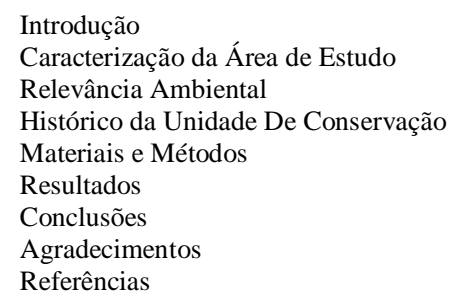

Diego Idelfonso de OLIVEIRA, Ricardo Galeno Fraga de Araújo PEREIRA

Universidade Federal da Bahia. Instituto de Geociências. Rua Barão de Jeremoabo, s/n - Ondina, Salvador - BA E-mails:

RESUMO - Uma Área de Proteção Ambiental (APA) tem como objetivos básicos proteger a diversidade biológica, disciplinar o processo de ocupação e assegurar a sustentabilidade do uso dos recursos naturais. As Lagoas e Dunas do Parque do Abaeté são os últimos remanescentes de sistemas de dunas, lagoas e restingas ainda conservadas no município de Salvador, Bahia. Apesar de estarem protegidas legalmente, encontram-se sujeitas a descaracterização pela intensificação do processo de ocupação urbana e especulação imobiliária ao longo da área costeira, acarretando a progressiva degradação de seus componentes físicos, químicos e biológicos. O objetivo deste trabalho foi analisar o estado de conservação da APA Lagoas e Dunas do Abaeté pela utilização do mapeamento do meio biofísico e avaliação dos conflitos ambientais existentes, com auxílio do uso de geotecnologias. Os resultados da análise espaçotemporal, entre os anos de 1976 e 2017, mostram que houve um crescimento de áreas urbanizadas dentro da APA de $1.161 \%$, enquanto neste mesmo período a classe das lagoas foi reduzida em $14 \%$, as dunas reduzidas em $21 \%$ e a vegetação nativa reduzida em $35 \%$. $\mathrm{O}$ intervalo de maior expansão urbana foi de 1976 a 1989, motivado, principalmente, pela implantação do Polo Petroquímico de Camaçari. Palavras-chave: Áreas de Proteção Ambiental, Lagoa do Abaeté, Geoconservação, Sensoriamento Remoto.

\begin{abstract}
An Environmental Protection Area (APA) has the main objectives of protecting biological diversity, disciplining the occupation process and ensuring the sustainability use of natural resources. The APA das Lagoas e Dunas do Abaeté is the last urban sources of the ecosystem of dunes, lagoons and restinga still conserved in the city of Salvador, Bahia. Although legally protected, the APA is loosing its single characteristics due to the intensifying process of urban occupation and real estate speculation along the coastal area, leading to the progressive degradation of its physical, chemical and biological components. The present work had as general objective to map and characterize biophysical environmental aspects and environmental conflicts existing in the APA Lagoas and Dunas do Abaeté, using the application of geotechnologies. From the space-time analysis, between 1976 and 2017, it was possible to observe a growth of urban areas within the APA of $1.161 \%$, while in this same period the class of the lagoons were reduced by $14 \%$, the dunes reduced by $21 \%$ and vegetation reduced by 35\%. The interval of greatest urban expansion was from 1976 to 1989 , driven by the implantation of the Petrochemical Complex of Camaçari.
\end{abstract}

Keywords: Environmental Protection Areas, Abaeté Lagoon, Geoconservation, Remote Sensing.

\section{INTRODUÇÃO}

As Lagoas e Dunas do Abaeté são o último remanescente de sistemas de dunas, lagoas e restingas ainda conservadas no município de Salvador, Bahia (UNIDUNAS, 2017). Estas unidades, apesar de estarem protegidas legalmente (CONAMA, 2002, 2003), encontram-se sujeitas a descaracterização pela intensificação do processo de ocupação urbana e especulação imobiliária ao longo da área costeira, acarretando a progressiva degradação e destruição de seus componentes físicos, químicos e biológicos. Os principais conflitos ambientais apontados pelo INEMA (2017 a) são: retirada de areia das dunas, queimadas, especulação imobiliária, veículos nas dunas, disposição irregular do lixo e supressão da flora nativa.

Em 1987, foi criada a APA Lagoas e Dunas do Abaeté, com o objetivo de preservar os ativos da geodiversidade e controlar a ocupação na área, mais especificamente as dunas e lagoas do Abaeté. A APA faz parte da Reserva da Biosfera da Mata Atlântica - RBMA, e possui em seu perímetro o Parque das Dunas, reconhecido pela UNESCO como um Posto Avançado da Reserva da Biosfera da Mata Atlântica.

Este trabalho tem como objetivo geral realizar uma análise espaço-temporal do meio biofísico e 
os conflitos ambientais existentes na APA Lagoas e Dunas Abaeté, com auxílio das geotecnologias, a fim de contribuir para a sua gestão ambiental. Os objetivos específicos foram: organizar e compilar as informações espaciais disponíveis, construindo um banco de dados georreferenciados, com a utilização de produtos de livre distribuição; organizar e compilar a legislação que permeia esta unidade de conservação; fazer uma análise da efetividade do seu zoneamento; analisar o conflito ambiental recorrente da APA, com a proposta de ampliação do aeroporto de Salvador e projetar um cenário futuro para a área.

\section{CARACTERIZAÇÃO DA ÁREA DE ESTUDO}

A área de proteção ambiental (APA) Lagoas e Dunas do Abaeté é uma unidade de conservação (UC) cuja gestão compete ao Instituto do Meio Ambiente e Recursos Hídricos - INEMA. Está localizada na porção extrema nordeste de Salvador, compreendendo os bairros de Itapuã, Stella Mares e Praia do Flamengo, entre as coordenadas geográficas $38^{\circ} 21^{\prime} 47^{\prime}$ ' W, $12^{\circ} 57^{\prime} 1^{\prime}$ ' S e $38^{\circ} 18^{\prime}$ $41^{\prime \prime} \mathrm{W}, 12^{\circ} 54^{\prime} 28^{\prime \prime}$ S. Estão inseridos na APA dois parques: Parque Metropolitano Lagoas e Dunas do Abaeté (administrado pelo INEMA) e Parque das Dunas (administrado pela Universidade Livre das Dunas e Restinga de Salvador - UNIDUNAS)
(Figura 1) (INEMA, 2017 a, b; UNIDUNAS, 2017).

Apresenta ambiente típico de restinga, com lagoas de coloração escura, intercaladas por dunas de areia branca, móveis, semimóveis ou fixas, recobertas por vegetação arbórea, arbustiva e herbácea que desempenha um papel relevante na fixação das dunas e proteção do sedimento contra a erosão. A fauna se destaca, com grande variedade de animais silvestres. Também é cenário de manifestações culturais como cultos afro-baianos e festejos para os santos da igreja católica (INEMA, 2017 a).
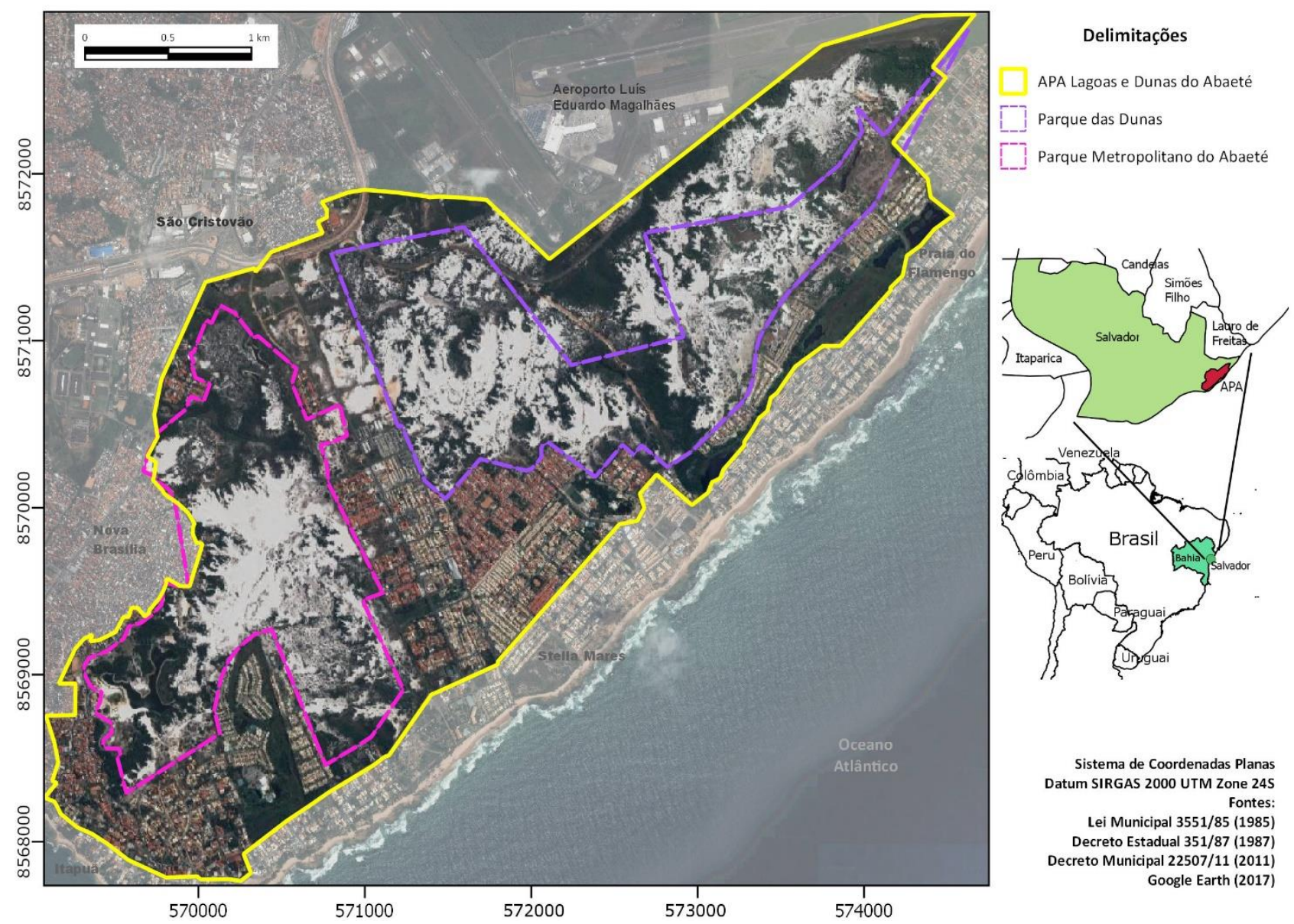

Figura 1 - Localização e situação da APA Lagoas e Dunas do Abaeté e seus parques municipais.

O clima no munícipio de Salvador sofre forte influência da maritimidade, o que resulta em umidade e salinidade elevadas e baixa amplitude térmica, com temperatura média de $25,3^{\circ} \mathrm{C}$, sendo classificado como tipo climático úmido (segundo metodologia de Thornthwaite \& Matther, 1955) ou tropical chuvoso de floresta sem estação seca (pela tipologia climática de Köppen). O balanço hídrico 
do período de 1961 a 1990 indicam precipitação média de 2.098,9 mm/ano, com as chuvas concentradas entre abril e julho, e excedente hídrico de 694,2 mm/ano (SEI, 1999).

A região do Abaeté está no contexto geológico regional dos depósitos quaternários presentes na Zona Costeira do Estado da Bahia (figura 2), aflorando sedimentos inconsolidados dos Depósitos de Leques Aluviais Pleistocênicos (QPla), Depósitos de Areias Litorâneas Regressivas Pleistocênicas (QPl) e Depósitos Eólicos Pleistocênicos (Qpe) (Dominguez \& Bittencourt, 2012).

Estas dunas tipo blow out são representantes dos depósitos Qpe, sendo a principal forma de relevo registrada na área, alcançado altitudes de $15-55 \mathrm{~m} \mathrm{e}$ com pequenas lagoas ou terras úmidas ocupando as bacias de deflação.

Parte das dunas encontra-se com a morfologia modificada, seja por erosão natural, seja pela ação antrópica relacionada à ocupação urbana e turística e pela exploração das areias como material para construção civil, o que é identificado através da redução de altura, modificação dos ângulos de inclinação de barlavento e sotavento, presença de ravinas, cortes e cicatrizes de retirada de vegetação de cobertura.

A área de estudo encontra-se na porção sudoeste das bacias hidrográficas do Ipitanga e Jaguaribe. A rede de drenagens é escassa e irregular, devido à alta permeabilidade das areias das dunas (Moraes, 1997).

A vegetação é, essencialmente, de restinga, apresentando estrato herbáceo, arbustivo e arbóreo. Esse tipo de vegetação é de forte instabilidade, devido ao tipo de substrato ao qual está relacionada. Os sedimentos que formam as dunas estão constantemente sobre ação de fatores erosivos, o que dificulta a manutenção e expansão das restingas (BRASIL, 1981).

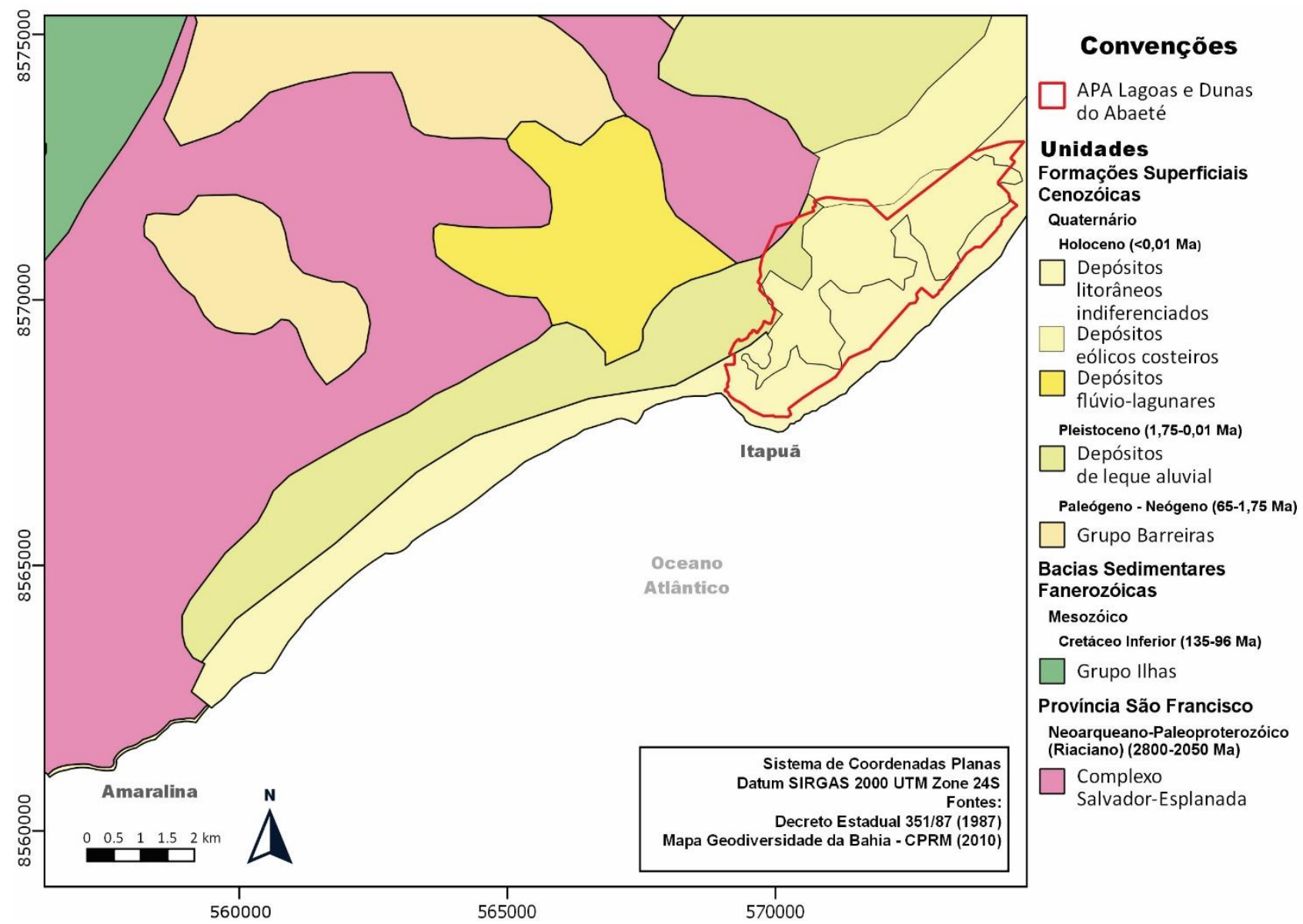

Figura 2 - Mapa simplificado da geologia de Salvador.

\section{RELEVÂNCIA AMBIENTAL}

A APA Lagoas e Dunas Abaeté faz parte da Reserva da Biosfera da Mata Atlântica - RBMA, que inclui todos os tipos de formações florestais e outros ecossistemas terrestres e marinhos que compõem o Domínio Mata Atlântica, bem como os principais remanescentes florestais e a maioria das unidades de conservação da Mata Atlântica (RBMA, 2004). O Conselho Nacional Reserva da Biosfera da Mata Atlântica - CN-RBMA (2008) define o local como Zona de 
Amortecimento e Conectividade (ZA), cujo objetivo é de minimizar os impactos ambientais negativos sobre estes núcleos e promover a qualidade de vida das populações da área, especialmente as comunidades tradicionais.

Segundo UNIDUNAS (2013), em 2014 o Parque das Dunas, UC municipal incluída na APA Lagoas e Dunas Abaeté, foram aclamadas como Posto Avançado da Reserva da Biosfera da Mata Atlântica, pelo desenvolvimento das funções básicas do RBMA: proteção da biodiversidade, desenvolvimento sustentável e do conhecimento científico e tradicional sobre a Mata Atlântica.

Os postos avançados são centros de divulgação das ideias, conceitos, programas e projetos desenvolvidos pela Reserva (RBMA, 2004).

\section{HISTÓRICO DA UNIDADE DE CONSERVAÇÃO}

A partir dos anos 70, a expansão urbana e o crescimento demográfico de Salvador na orla atlântica alcançam Itapuã, exercendo forte pressão sobre a área da Lagoa do Abaeté, relacionada com as ocupações e invasões nos terrenos do entorno (Oliveira et al., 2010).

Neste período foi implantado o Parque Municipal Abaeté, através do Sistema de Áreas Verdes do Munícipio, sendo o primeiro esforço do poder público da cidade em resguardar as condições ambientais e paisagísticas do local.

$\mathrm{Na}$ década seguinte, através do Decreto Estadual $n^{\circ}$ 351/87, foi criada a APA Lagoas e Dunas do Abaeté, com a importância de proteger o último remanescente de sistemas de dunas, lagoas e restingas ainda conservado no município de Salvador (INEMA, 2017a).

A APA passou por frequentes mudanças na delimitação do seu perímetro e zoneamento, sendo o primeiro Zoneamento EcológicoEconômico (ZEE) estabelecido em 1993, com o Decreto Estadual no 2540/93 e posteriormente alterado nos anos de 1998 e 2002.

O plano de manejo da APA foi divulgado em 1997, desenvolvido pela Companhia de Desenvolvimento Urbano do Estado da Bahia CONDER, que considerou a área possuidora de
Os resultados do Projeto de Avaliação e Ações Prioritárias para Conservação da Biodiversidade da Mata Atlântica e Campos Sulinos classificam a região da APA como área de alta importância biológica, sendo área prioritária para peixes, invertebrados e flora (MMA, 2000). É a única APA com seu perímetro totalmente contido dentro do município de Salvador, sendo também a mais antiga APA instituída no Estado da Bahia.

A região da APA é importante representante da geodiversidade de Salvador e, segundo Pinto (2014), foi classificada como um geossítio de relevância nacional, sendo um registro preservado dos depósitos litorâneos que se estendem pela costa de Salvador, desde Itapuã até o bairro de Amaralina (Carvalho \& Ramos, 2010).

atributos ambientais relevantes que potencializam a implantação de um micro polo de desenvolvimento turístico e uma nova alternativa para implantação de serviços hoteleiros no Município de Salvador (CONDER, 1997).

Para auxiliar na definição e na gestão de espaços territoriais especialmente protegidos, foi instituído, no ano de 2000, o Sistema Nacional de Unidades de Conservação da Natureza - SNUC, que estabelece critérios e normas para a criação, implantação e gestão das unidades de conservação no país, possibilitando, com isso, uma melhor gestão do patrimônio ambiental brasileiro (MMA, 2017).

Em 2011, é implantado através do Decreto Municipal 22.507/11, o Parque das Dunas. Inserido na APA Lagoas e Dunas do Abaeté, compreende uma área de aproximadamente seis milhões de metros quadrados (UNIDUNAS, 2017).

Seu uso é limitado aos fins científicos, culturais, educativos, turísticos e recreativos, respeitando a integridade dos ecossistemas naturais nele existentes (SALVADOR, 2012).

A Figura 3 apresenta uma síntese dos eventos mais marcantes na evolução histórica da APA.

\section{MATERIAIS E MÉTODOS}

A figura 4 apresenta o fluxograma dos métodos aplicados. O primeiro passo do trabalho consistiu em consultar a legislação relacionada à criação da APA, do seu ZEE, dos parques municipais e do projeto de ampliação do aeroporto internacional de Salvador, com a finalidade de se obter as coordenadas que os delimitam. 
Através do software Qgis 2.14 Essen, as coordenadas coletadas nos decretos foram convertidas em shapefiles, gerando como produtos: delimitação da APA, delimitação dos parques municipais, delimitação da área pretendida para a ampliação do aeroporto. Para o zoneamento de 2002, foi feito o georreferenciamento do mapa anexado no decreto de criação da APA.
Para a análise espaço-temporal da área de estudo foram consideradas os anos de 1976, 1989, 1998, 2006 e 2017.

Como base para o mapeamento, foram utilizadas fotografias aéreas disponíveis no catálogo de serviços da CONDER e imagens orbitais fornecidas pelo aplicativo Google Earth Pro, os produtos utilizados estão especificados na tabela 1.

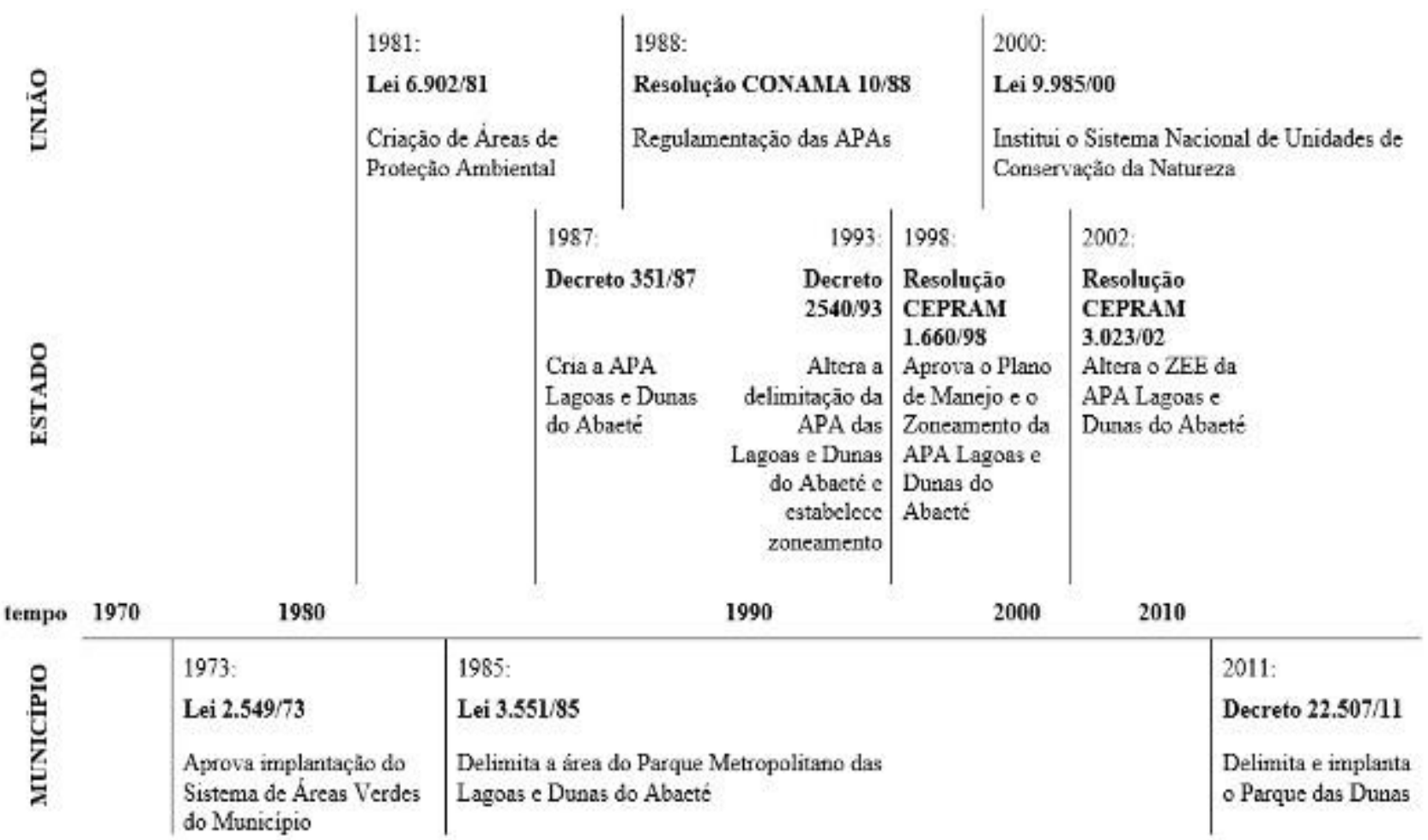

Figura 3 - Síntese do histórico legal referente à APA Lagoa e Dunas do Abaeté e seus parques.
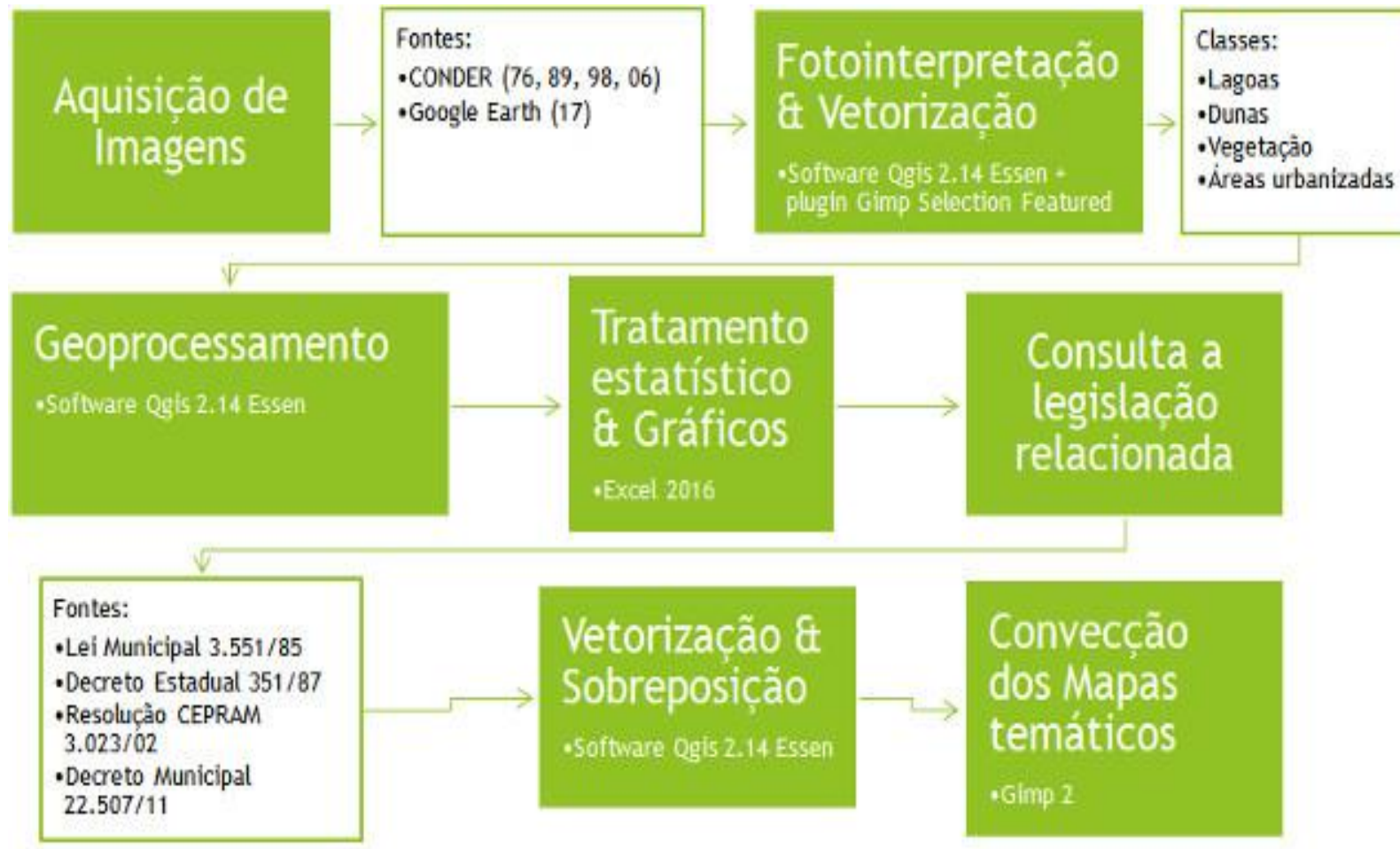

Figura 4 - Fluxograma da metodologia aplicada ao trabalho. 
Tabela 1 - Especificações dos produtos utilizados como base.

\begin{tabular}{c|c|c|c}
\hline Anos & Produto & Escala & \multirow{2}{*}{ Fonte } \\
\cline { 1 - 2 } 1976 & Mosaico de Salvador 1976 & $1: 8.000$ & \multirow{2}{*}{$\begin{array}{c}\text { http://www.informs.conder.ba. } \\
\text { gov.br/catalogo-servicos/ }\end{array}$} \\
\hline 1989 & Mosaico de Salvador 1989 & $1: 8.000$ & \\
\hline 1998 & Mosaico Região Metropolitana de Salvador 1998 & $1: 8.000$ & https://www.google.com/earth/ \\
\hline 2006 & Ortofoto Salvador 16cm 2006 & $\begin{array}{c}\text { resolução espacial de } \\
30 \mathrm{~m}\end{array}$ & \\
\hline
\end{tabular}

Após a fotointerpretação das imagens, a vetorização foi realizada com a utilização do software Qgis 2.14 Essen, com auxílio do plugin Gimp Selection Featured, que permitiu aumentar o contraste de cores das imagens, a seleção automática de áreas contínuas com pixels semelhantes, e exportar para dentro do ambiente Qgis como shapefiles. Foram consideradas quatro classes conforme descrito a seguir:

- Lagoas: compreendem os corpos hídricos lenticulares e/ou irregulares, de água com coloração escura, com regimes perenes ou intermitentes.

- Dunas: compreendem as áreas com areias sem vegetação, de coloração branca.

- Vegetação: compreende as áreas de restinga e áreas úmidas com vegetação.
- Áreas urbanizadas: compreendem as áreas com edificações, infraestrutura, áreas verdes e áreas desmatadas.

Para cada aspecto foi gerado um layer específico, sendo possível quantificar sua extensão em área. Com os layers gerados para cada ano foram realizadas operações de geoprocessamento, de diferença e interseção, dentro do Qgis 2.14 Essen, a fim de analisar acréscimos e decréscimos de áreas. $\mathrm{O}$ tratamento estatístico destes dados e a representação através de gráficos foram feitos com a utilização do software Excel 2016. O zoneamento foi sobreposto a imagem mais recente (2017) a fim de identificar conflitos ambientais. Para confecção dos mapas finais como figuras foi utilizado o editor de imagens Gimp 2.

\section{RESULTADOS}

Na tabela 2 está representado o quantitativo das áreas, em hectares, de cada classe mapeada para os anos de 1976, 1989, 1998, 2006 e 2017. Pode-se perceber o avanço da ocupação urbana ocorrida no interior da APA, que resultou, consequentemente, na redução de suas feições naturais.

Dentre os elementos naturais, o mais afetado

foi a vegetação. Enquanto em 1976 a mesma cobria $46,5 \%$ da área total que representa a APA, hoje cobre $30,2 \%$. As dunas e lagoas também foram suprimidas ao longo do intervalo do estudo, sofrendo um decréscimo relativo final de $-21 \%$ e $-14 \%$, respectivamente. O mapeamento sequencial da área da APA é exposto na figura 5.

Tabela 2 - Quantificação das áreas dos aspectos mapeados, por ano.

\begin{tabular}{c|c|c|c|c|c|c|c|c}
\hline & \multicolumn{2}{|c|}{ Lagoas } & \multicolumn{2}{c|}{ Dunas } & \multicolumn{2}{c}{ Vegetação } & \multicolumn{2}{c}{ Áreas Urbanizadas } \\
\hline Anos & ha & \% & ha & \% & ha & \% & ha & \% \\
\hline 1976 & 46,5 & 3,7 & 597,2 & 47,5 & 584,7 & 46,5 & 28,9 & 2,3 \\
\hline 1989 & 51,6 & 4,1 & 629,9 & 50,1 & 409,9 & 32,6 & 166,0 & 13,2 \\
\hline 1998 & 47,8 & 3,8 & 490,4 & 39,0 & 391,0 & 31,1 & 329,4 & 26,2 \\
\hline 2006 & 44,0 & 3,5 & 467,7 & 37,2 & 408,6 & 32,5 & 338,2 & 26,9 \\
\hline 2017 & 40,2 & 3,2 & 471,5 & 37,5 & 379,7 & 30,2 & 364,6 & 29,0 \\
\hline $\begin{array}{c}\text { Incremento } \\
\text { ('76-'17) }\end{array}$ & $-6,3$ & -14 & $-125,7$ & -21 & $-204,9$ & -35 & $+335,7$ & +1.161 \\
\hline
\end{tabular}

O intervalo entre 1976 e 1989 foi o que apresentou maior supressão da vegetação, com uma perda relativa de $30 \%$. Este mesmo período marca uma explosão na ocupação urbana dentro APA, com um incremento relativo de $474 \%$ de áreas urbanizadas (Figura 6). Dos motivadores deste avanço pode-se destacar: a implantação do Polo Petroquímico de Camaçari e as invasões em Itapuã (Oliveira et al, 2010). Este crescimento da cidade no entorno da Lagoa do Abaeté, possivelmente, influenciou na decisão de implantação da APA, que ocorreu em 1987. 

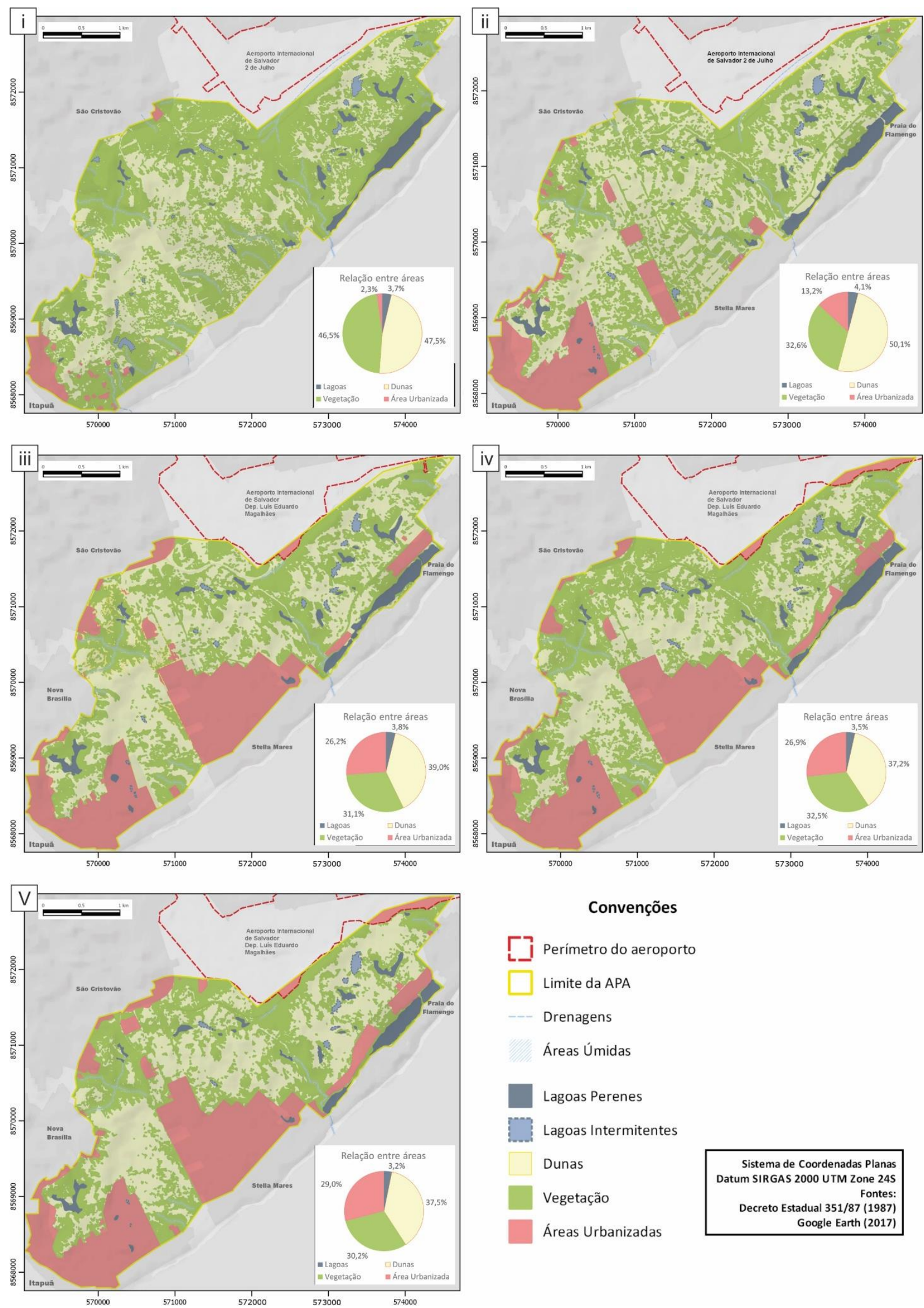

Convenções

Г] Perímetro do aeroporto

Limite da APA

Drenagens

Áreas Úmidas

Lagoas Perenes

Lagoas Intermitentes

Dunas

Vegetação

Áreas Urbanizadas

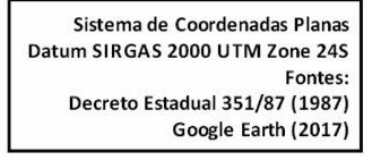

Figura 5 - Mapa da situação da APA para os anos de 1976 (i), 1989 (ii), 1998 (iii), 2006 (iv) e 2017 (v).

Segundo o Decreto Estadual 351/87 (BAHIA, 1987): “(...) considerando que as ações humanas atualmente incidentes sobre a área do Abaeté, pela sua característica predatória, poderão conduzir à desfiguração e, provavelmente, destruição do ecossistema duna/ lagunar (...)". 


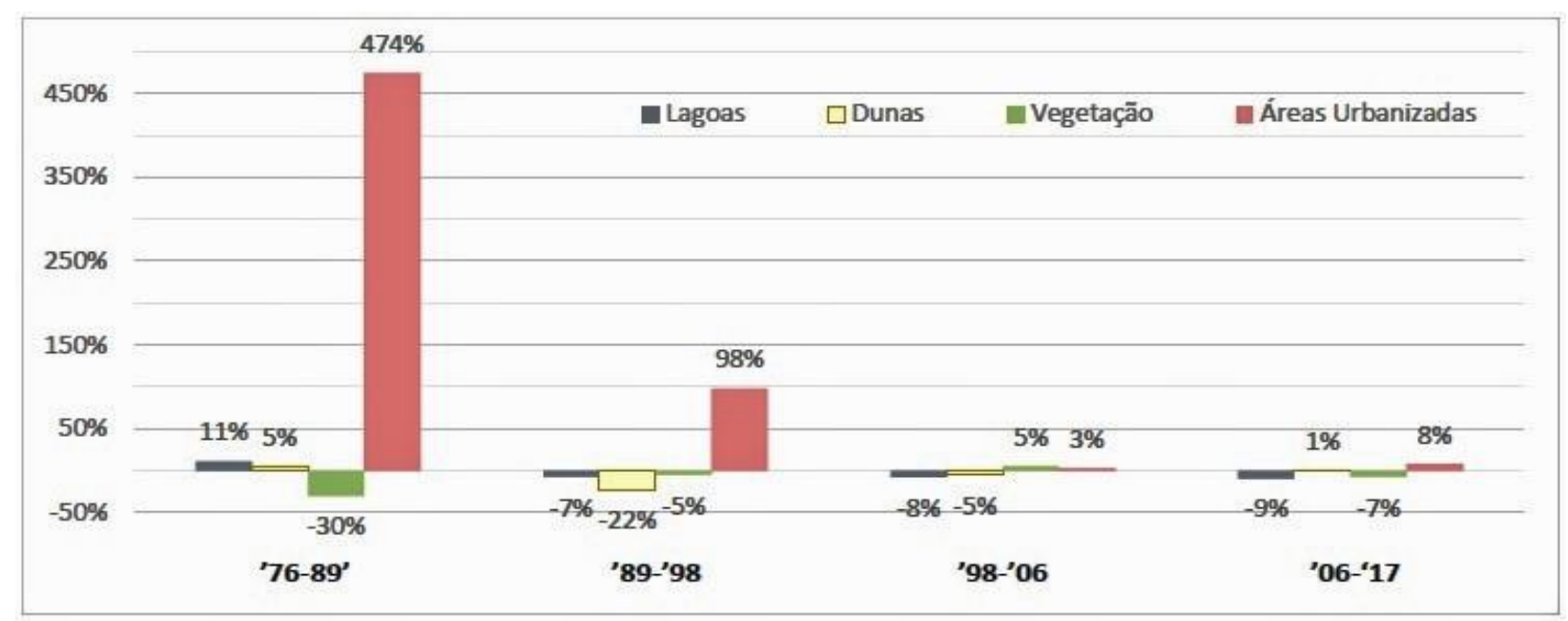

Figura 6 - Crescimento/decréscimo relativo de cada classe, por intervalo amostral.

O crescimento do tecido urbano continuou na década seguinte, de modo que se observa que o incremento relativo de áreas urbanas praticamente dobrou para o intervalo entre 1989 e 1998. Este avanço pode ser enquadrado em dois eixos.

Um eixo localizado na porção litorânea da APA, em que ocorrem empreendimentos hoteleiros e condomínios fechados, considerados de alto padrão, residências e comércios locais, com a consolidação dos bairros de Stella Maris e Praia do Flamengo.

O outro eixo, na porção continental, é caracterizado pelo crescimento dos bairros de Itapuã e São Cristóvão, áreas consideradas como de baixa renda, compreendendo a faixa com receitas entre um e três salários mínimos, expansão da Avenida Paralela e do aeroporto, e invasões no interior do perímetro da APA

Neste intervalo houve duas propostas de zoneamento da APA, sendo uma em 1993 e outra em 1998. Ambas as propostas foram elaboradas pela Companhia de Desenvolvimento Urbano do Estado da Bahia - CONDER, tendo como foco: a tentativa de controle da expansão urbana e a preservação do sistema de lagoas e dunas, que sofreu perda de $30 \%$ de sua vegetação no primeiro espaço amostralNo período de 1998 a 2006, as dunas foram as feições naturais que apresentaram a maior supressão, podendo ter sido este fato decorrente da perda da vegetação, que atua como fixadora para as areias destas geoformas.

O crescimento urbano promoveu como consequência a impermeabilização do solo, soterramento e canalização de diversas drenagens e diminuição das áreas de recargas, que se refletem no sucessivo decréscimo das áreas correspondentes às lagoas.

Pela análise da imagem aérea do ano de 2017, foi possível observar o avanço da malha urbana nas bordas da zona de proteção visual, situação contrária ao parâmetro ambiental definido para esta zona, que proíbe qualquer parcelamento do solo e a supressão de vegetação fixadora das dunas. Tal cenário é representado na figura 7 , onde são apresentados os conflitos ambientais identificados na área.

Em campo foram constatados os impactos na APA, decorrentes da ocupação comentada no parágrafo anterior, com destaque para construções e ocupação dentro do sistema dunar, retirada de areia, deposição de lixo e entulho, trafego de veículos sobre as dunas, postos de gasolina (fonte potencial de poluentes) e edificações com mais de dois pavimentos, infringindo a norma do ZEE (Figura 8).

O Decreto Estadual $n^{\circ} 15.912$ de 30 de janeiro de 2015 estabelece em seu texto a desapropriação de mais de 262 ha, divididas em duas áreas, que se destinam à execução das obras de ampliação do Aeroporto Internacional de Salvador Deputado Luís Eduardo Magalhães (Figura 6). Porém estas áreas estão contidas dentro da poligonal da APA, em terreno com vegetação fixadora de dunas, o que, considerando o Código Florestal (Lei 12.652, de 25/Mai/2012) e a criação do Parque das Dunas (Decreto Municipal 22.507/11), caracteriza um conflito ambiental.

O projeto de ampliação está previsto no plano de manejo da APA do Abaeté, que estabeleceu a zona de uso específico (ZUE) para este fim, em conformidade com a Lei $n^{\circ} 9.985$, de 18 de julho de 2000, Parágrafo único: "Até que seja elaborado o Plano de Manejo, todas as atividades e obras desenvolvidas nas unidades de 
conservação de proteção integral devem se limitar àquelas destinadas a garantir a integridade dos recursos que a unidade objetiva proteger (...)”. Entretanto, na área destinada à desapropriação estão contidas mais de doze lagoas, além da vegetação de restinga e das próprias dunas, sendo todas caracterizadas como APPs e objetos da proteção da APA.
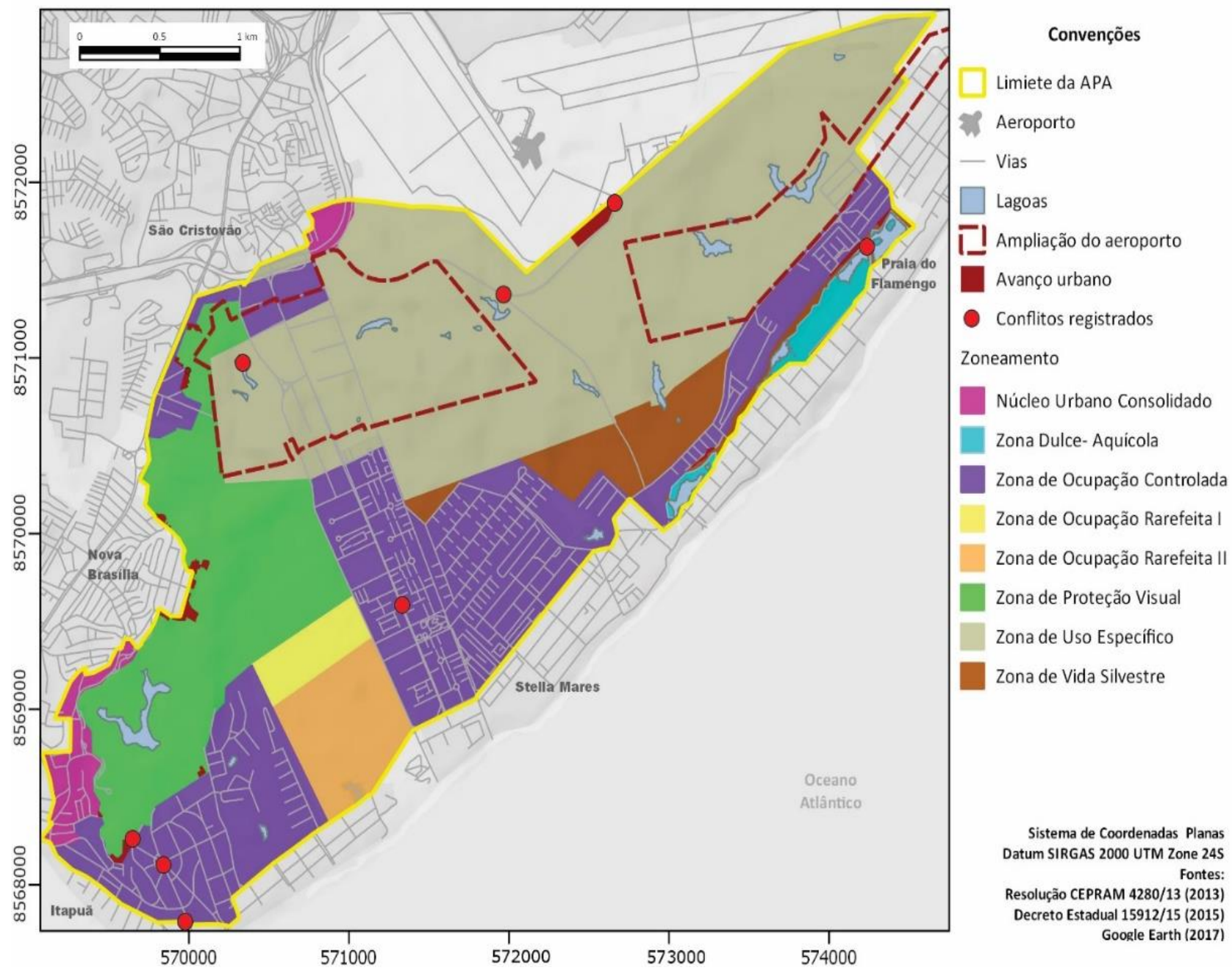

Figura 7 - Mapa de ZEE com conflitos ambientais em destaque.

De acordo com a Resolução CONAMA $n^{\circ}$ 369, de 28 de março de 2006, Art. 3: "A intervenção ou supressão de vegetação em APP somente poderá ser autorizada quando o requerente, entre outras exigências, comprovar: I - a inexistência de alternativa técnica e locacional às obras, planos, atividades ou projetos propostos (...)". No Plano Diretor PDIR, elaborado pela INFRAERO, constam quatro alternativas de ampliação do aeroporto, das quais apenas uma delas não contempla a ocupação da área das dunas.

Entre os impactos negativos no meio físico, o IMA (2015) destaca em seu relatório:

- possibilidade de instabilidade geomorfológica no sistema de dunas;

- $\quad$ supressão de lagoas e brejos e implicações na qualidade da água;

- $\quad$ redução da vegetação nativa, com supressão de restinga, brejos e lagoas associadas;

- redução da área disponível para fauna;

- perda de áreas para atividades de lazer, educacionais e científicas;

- desapropriação de áreas urbanas.

Uma projeção do cenário futuro da APA é exposta na Figura 9. Para gerar esta estimativa, foram consideradas

- a ocupação por infraestrutura das áreas definidas para ampliação do aeroporto mais a área atual do aeroporto, e

- a ocupação urbana das zonas destinadas para este fim (NUC, ZOC, ZOR I e ZOR II) mais a ocupação irregular existente hoje na APA.

- Neste cenário, $56,1 \%$ da área da APA estariam ocupados por feições não naturais (Tabela 3) e treze lagoas seriam afetadas diretamente. 

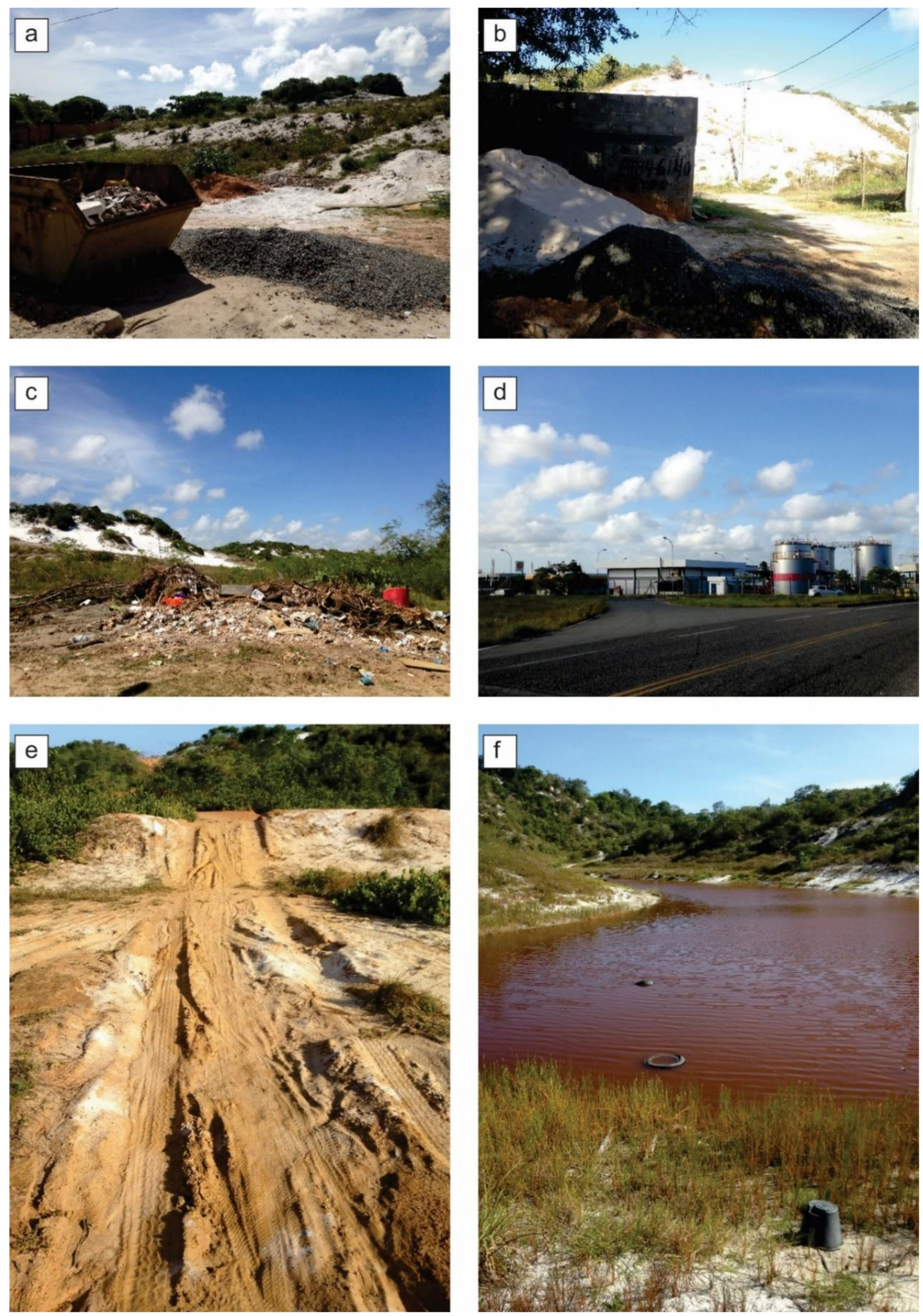

Figura 8 - Alguns conflitos ambientais registrados na área da APA: Construções indevidas na ZPV (8568247mN, $569595 \mathrm{mE})$ e $(8569799 \mathrm{mN}, 570119 \mathrm{mE})$ a e b); lixo e entulho na ZPV (8568265mN, 569661mE) c); reservatório de combustível $(8571874 \mathrm{mN}, 572672 \mathrm{mE})$ d); marcas de pneu sobre as dunas $(8571353 \mathrm{mN}, 571978 \mathrm{mE})$ e); lixo nas águas da lagoa Yemanjá $(8570964 \mathrm{mN}, 570345 \mathrm{mE}) \mathbf{f})$. 


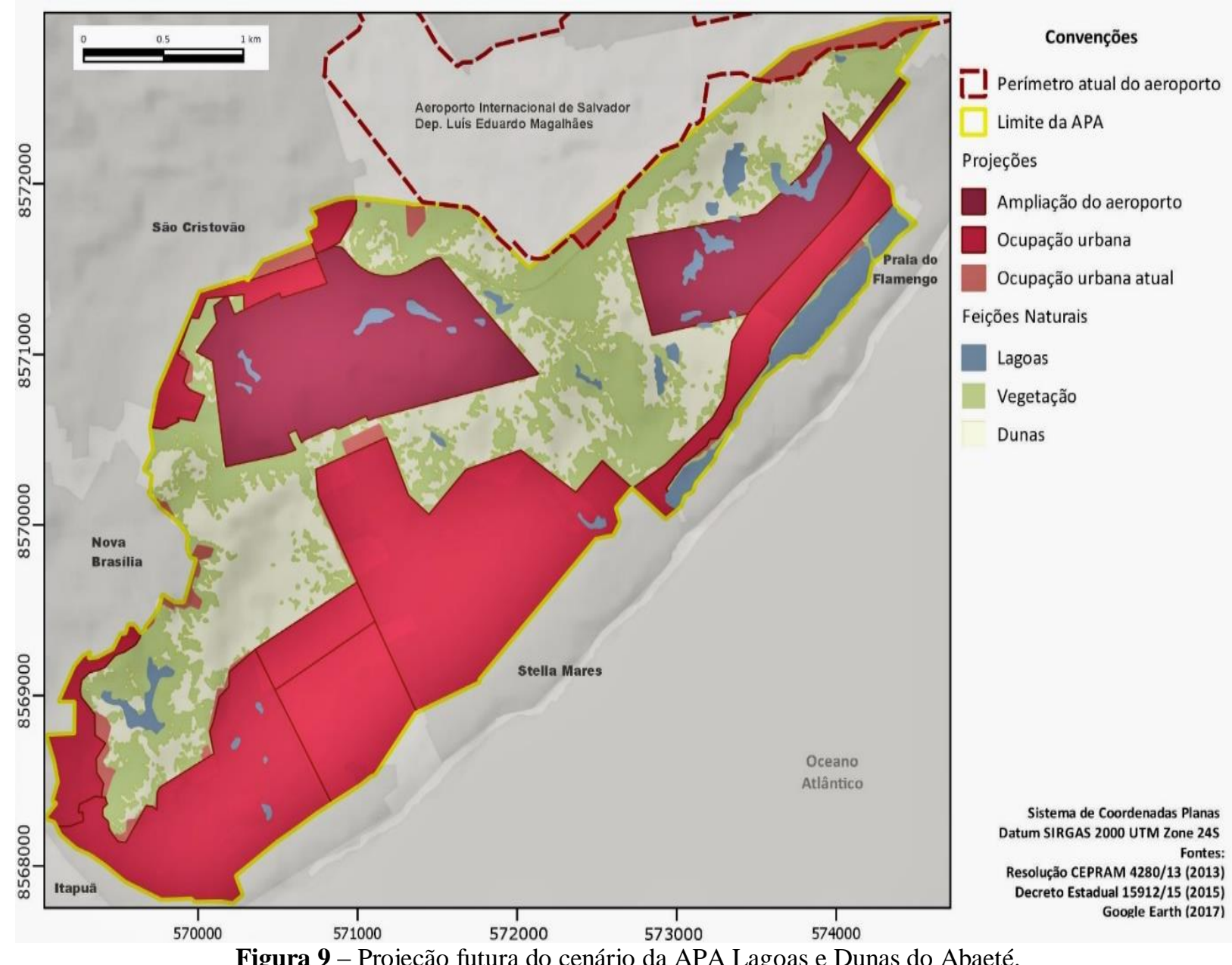

Tabela 3 - Quantificação das áreas da projeção futura da APA.

\begin{tabular}{c|c|c}
\hline Tipo de área & ha & \% \\
\hline Áreas destinadas à ocupação urbana (de acordo com o zoneamento) & 447,7 & 35,6 \\
\hline Áreas com ocupação urbana irregular e infraestrutura & 26,2 & 2,1 \\
\hline Áreas destinadas à ampliação do aeroporto de Salvador & 231,5 & 18,4 \\
\hline Total de áreas ocupadas por urbanização/infraestrutura & 705,4 & 56,1 \\
\hline Áreas naturais/preservadas & 551,9 & 43,9 \\
\hline
\end{tabular}

\section{CONCLUSÕES}

A análise por sensoriamento remoto permitiu constatar que a ocupação urbana ocorrida na APA e seu entorno acarretou danos ambientais que afetaram a integridade do sistema de lagoas, dunas e restingas do Abaeté. As áreas urbanizadas apresentaram um crescimento de $1.161 \%$ entre 1976 e 2017, enquanto neste mesmo período a classe das lagoas foi reduzida em 14\%, as dunas reduzidas em $21 \%$ e a vegetação reduzida em 35\%. O intervalo de maior expansão urbana foi de 1976 a 1989. O ritmo de supressão dos elementos naturais da APA foi reduzido de 1998 até 2017, o que indica um êxito na criação desta unidade e das políticas de conservação do local.
Porém a ocupação urbana irregular continua ocorrendo, o que, associada com a possibilidade de ampliação do aeroporto de Salvador sobre a área da APA, aponta um cenário de não conformidade com os objetivos da Unidade de Conservação, já que restariam apenas $43,9 \%$ de área protegida.

Frente a este cenário, recomenda-se às esferas governamentais uma revisão no planejamento urbano e zoneamento proposto no Plano de Manejo da APA das Lagoas e Dunas do Abaeté (CONDER, 1997). Tendo em consideração que a área abriga um dos últimos remanescentes de áreas naturais na cidade, que é também dotado de elevado valor cultural, as UC criadas nos 
arredores das Lagoas e Dunas do Abaeté representam importantes ativos da memória ambiental de Salvador e preservam elementos importantes da sua geodiversidade. Esta revisão do Plano de Manejo deve ter o objetivo de valorizar e conservar estes atributos relevantes da UC e conter a ocupação na zona de proteção visual da APA.

Ademais, sugere-se descartar o projeto de ampliação do Aeroporto Internacional Luís
Eduardo Magalhães sobre o Parque das Dunas, em favor de outras alternativas locacionais apresentadas em IMA (2015). Dentre estas alternativas, recomenda-se a ampliação do aeroporto sobre a área da atual Base Aérea de Salvador, ou a transferência do aeroporto internacional para o município de Feira de Santana ou São Sebastião do Passé, já que ambos disponibilizaram áreas mais adequadas para tal finalidade.

\section{AGRADECIMENTOS}

A toda equipe do Parque das Dunas, pelo apoio no decorrer da realização do trabalho.

\section{REFERÊNCIAS}

BAHIA. Decreto Estadual no 351 de 22 de setembro de 1987. Cria a Área de Proteção Ambiental - APA das Lagoas e Dunas do Abaeté, no município de Salvador, e dá outras providências. Disp. em: http://www.inema.ba.gov.br/wpcontent/uploads/2011/09/DECRETO-N\%C2\%BA-351-DE22-DE-SETEMBRO-DE-1987.pdf. Acessado em: 7 Out 2017.

BRASIL. MINISTÉRIO DAS MINAS E ENERGIA. SECRETARIA GERAL. Projeto RADAMBRASIL. Folha SD.24 Salvador: Geologia, Geomorfologia, Pedologia, Vegetação e Uso potencial da Terra. Rio de Janeiro, 624 p 1981.

CARVALHO, L.M.; RAMOS, M.A.B. (organização) Geodiversidade do estado da Bahia. Salvador: CPRM, 2010.

CN-RBMA - CONSELHO NACIONAL RESERVA DA BIOSFERA DA MATA ATLÂNTICA. Reserva da Biosfera da Mata Atlântica Fase VI/2008: revisão e atualização dos limites e zoneamento da Reserva da Biosfera da Mata Atlântica em base cartográfica digitalizada. São Paulo: Conselho Nacional da Reserva da Biosfera da Mata Atlântica, 127 p., 2008. Disponível em: <http://www.rbma.org.br/ rbma/rbma_fase_vi.asp> Acesso em: 15 Dez. 2017.

CONAMA - CONSELHO NACIONAL DO MEIO AMBIENTE. Resolução $\mathrm{n}^{\circ}$ 303, de 20 de março de 2002. Dispõe sobre parâmetros, definições e limites de Áreas de Preservação Permanente. Disp. em http://www.mma.gov.br/port/conama/res/res02/res30302.html. Acessado em: 15 Nov 2017.

CONAMA - CONSELHO NACIONAL DO MEIO AMBIENTE. Resolução $n^{\circ} 341$, de 25 de setembro de 2003. Dispõe sobre critérios para a caracterização de atividades ou empreendimentos turísticos sustentáveis como de interesse social para fins de ocupação de dunas originalmente desprovidas de vegetação, na Zona Costeira. Disp. em: http://www.mma.gov.br/port/conama/res/res03/res 34103.xml. Acessado em: 15 Nov 2017.

CONDER - Companhia de Desenvolvimento Urbano do Estado da Bahia. Plano de Manejo da Área de Proteção Ambiental das Lagoas e Dunas de Abaeté. Salvador, BA, 1997. Disp. em: http://www.inema.ba.gov.br/wp-content/files/Plano_de_

Manejo____Abaet.pdf. Acessado em: 7 Out 2017.

DOMINGUEZ, J.M.L.; BITTENCOURT, A.C.S.P. Zona Costeira do Estado da Bahia. In: Barbosa, J.S.F. (coordenação geral). Geologia da Bahia: pesquisa e atualização. Salvador: CBPM (Série publicações especiais; 13 v.2), p.395-425, 2012.

IMA - Instituto do Meio Ambienta. Processo $\mathrm{n}^{\circ}$ 2009008453/TEE/LL-0018. Requerente: INFRAERO - Empresa Brasileira de Infraestrutura Aeroportuária. 2015

INEMA - INSTITUTO DO MEIO AMBIENTE E RECURSOS HIIDRICOS. Abaeté - Parque Metropolitano Lagoas e Dunas do Abaeté. Disp. em: http://www.inema.ba.gov. br/gestao-2/parques-metropolitanos/parque-metropolitano- lagoas-e-dunas-do-abaete/. Acessado em: 7 Out 2017.

INEMA - INSTITUTO DO MEIO AMBIENTE E RECURSOS HÍDRICOS. APA Lagoas e Dunas do Abaeté. Disp. em: http://www.inema.ba.gov.br/gestao-2/unidades-deconservacao/apa/apa-lagoas-e-dunas-do-abaete/. Acessado em: 7 Out 2017.

MMA - MINISTÉRIO DO MEIO AMBIENTE. Avaliação e ações prioritárias para a conservação da biodiversidade da Mata Atlântica e Campos Sulinos. Brasília: MMA/SBF, 40 p., 2000.

MORAES, J.W.O. Avaliação geofísica do sistema de aquífero na área do Parque das Lagoas e Dunas do Abaeté. Salvador, 1997. 103 p. Dissertação (Graduação em Geofísica) - Instituto de Geociências, Universidade Federal da Bahia.

OLIVEIRA, O.J.R, OLIVEIRA, M.F.S; OLIVEIRA, C.F.S. Ambiente, Cultura e Turismo: o Caso da Lagoa do Abaeté. In: V ENCONTRO NACIONAL DA ANPPAS. Florianópolis, 2010. Atas...Florianópolis.

PINTO, A.B.C. Geodiversidade e Patrimônio Geológico de Salvador: uma diretriz para a Geoconservação e a Educação em Geociências. Tese (Doutorado). Universidade Federal da Bahia, Instituto de Geociências, 211p., 2014.

RBMA - RESERVA DA BIOSFERA DA MATA ATLÂNTICA. Texto Síntese, 2004. Disp. em: http://www.rbma.org.br/rbma/rbma_1_textosintese.asp. Acesso em 15 Dez 2017.

SEI - SUPERINTENDÊNCIA DE ESTUDOS ECONÔMICOS E SOCIAIS DA BAHIA. Balanço hídrico do estado da Bahia. Salvador: SEI, Série Estudos e Pesquisas, 45, 250 p., 1999.

THORNTHWAITE, C.W. \& MATHER, J.R. The water balance. Centerton, NJ: Drexel Institute of Technology Laboratory of Climatology, 1955. 104p. (Publications in Climatology, vol. VIII, n.1)

UNIDUNAS - UNIVERSIDADE LIVRE DAS DUNAS E RESTINGA DE SALVADOR. Apresentação. Disp. em: http://unidunas.com.br/apresentacao/. Acesso em 7 Out 2017.

UNIDUNAS - UNIVERSIDADE LIVRE DAS DUNAS E RESTINGA DE SALVADOR. Parque das Dunas é posto avançado da Reserva da Biosfera da Mata Atlântica, 5 Dez 2013. Disp. em: http://unidunas.com.br/parque-das-dunas-eposto-avancado-da-reserva-da-biosfera-da-mata-atlantica/. Acesso em 15 Dez 2017. 